\title{
Challenges and Benefits of the Use of AASHTOWare for 3 Climatic Regions in Turkey
}

\author{
Beyhan IPEKYUZ ${ }^{1}$ \\ Hediye TUYDES YAMAN ${ }^{2}$ \\ Hande Isik OZTURK ${ }^{3}$
}

\begin{abstract}
The economic growth in developing countries triggers investments in highway networks. Thus, this requires a re-evaluation of existing design practices, which are mostly empirical. An alternative is the relatively recently developed Mechanistic-Empirical (M-E) design method. It has major data challenges and must be identified before a major switch. In this study, three different climatic regions for Turkey were analyzed optimizing 162 design combinations. Results showed that climate, traffic, and reliability parameters extremely affect the performance of the pavement. As in the current practice of Turkey, climate and material effects are not currently considered; these should be further studied considering the local calibration steps.
\end{abstract}

Keywords: Mechanistic-Empirical design method, AASHTOWare, AASHTO, flexible pavement, pavement design, climate.

\section{INTRODUCTION}

In both developed and developing countries, a considerable amount of gross national product is spent on the expansion and maintenance of the road networks [1]. It is important to evaluate these investments based on service life perspective and follow a pavement design guide considering the climate, traffic, environmental, subgrade, and material properties all at once, using a method capable of predicting distress mechanisms.

In Turkey, the General Directorate of Highway (GDH-KGM) was established in 1950 to construct, maintain, rehabilitate, and manage the intercity roadway network. Today, within

Note:

- This paper was received on September 15, 2020 and accepted for publication by the Editorial Board on July 7, 2021.

- Discussions on this paper will be accepted by November 30, 2022.

- https://doi.org/10.18400/tekderg.793889

1 Middle East Technical University, Department of Civil Engineering, Ankara, Turkey ipekyuzb@metu.edu.tr - https://orcid.org/0000-0001-8088-1896

2 Middle East Technical University, Department of Civil Engineering, Ankara, Turkey htuydes@metu.edu.tr - https://orcid.org/0000-0001-8088-1896

3 Middle East Technical University, Department of Civil Engineering, Ankara, Turkey ozturkha@metu.edu.tr - https://orcid.org/0000-0003-2053-992X 
their $30000 \mathrm{~km}$ network, it has about $17500 \mathrm{~km}$ flexible pavements, $13000 \mathrm{~km}$ chip seals and the rest is majorly stabilized and earth. It is targeted to upgrade the poor roadway segments with flexible pavements, and to add new corridors.

In pavement design, starting with the American Association of State Highways Officials (AASHO) Interim Guide of 1962, the GDH adopted the AASHTO methods. The latest version, based on AASHTO'93 design guideline [2], has been in use in Turkey as in many countries for the design of both flexible and rigid pavements even though it is stated to overestimate/underestimate layer thicknesses in most design cases, leading to either high initial construction cost or inadequate pavement performance under traffic loading during its service life [3]. Alternatively, the AASHTO has introduced the new Mechanistic-Empirical Pavement Design Guide (MEPDG) based on the Mechanistic-Empirical (M-E) design method. The M-E method is embedded in the AASHTOWare software [4], which considers the material properties, climate, subgrade type, reliability, etc. and, predicts performance for the entire service life of the pavement. This software computes the stresses, strains, and deflections through the life of the pavement and estimates the distresses with the help of distress transfer functions [5]; and it gained popularity in European countries such as Italy [6], Poland [7, 8], and Romania [9].

Applying MEPDG may provide long term economic and performance evaluations for highway investments in developing countries. Some studies focused on the application of the M-E method as a design technique were conducted in emerging economies, e.g., Qatar [10, 11], Egypt [12, 13], and the Kingdom of Saudi Arabia, lately [14].

Despite the interest in adopting the M-E design method for future road investments in developing countries, such as Turkey, there are still limited experience and study in switching to the M-E design because the data needs create a major challenge, which must be carefully assessed a priori, and is the main motivation behind this study. In the case of Turkey, Shakhan et al. [15] focused on the data collection needs for pavement design in the city of Izmir, Turkey but it fell short in creating any specific design. Ozturk et al. [16] is the only study to use the M-E method for rigid pavement design for 8 different cities in Turkey. This follow-up study aimed to support the discussion of the challenges and benefits of switching to the M-E method for flexible pavement design.

To evaluate the potential use of the M-E method for different design cases and compare the results with those of AASHTO'93, various design cases were created based on traffic conditions (low, medium, high), subgrade types, reliability levels, and surface course mixtures, and all of which were assumed to have a fixed service life of 20 years. As climatic conditions affect many of these aforementioned parameters directly, the pavement design cases were repeated for three different climatic (CL) regions (cold, rainy, and warm/Mediterranean) in Turkey.

AASHTOWare Pavement software Version 2.2 (AASHTOWare in short) was used to determine the optimum design thicknesses by iteratively varying these thicknesses to meet the target levels of distresses at the end of the life of the pavement. Following the research methodology for the rigid pavement design using the M-E design in [16], this study first charted the effect of selected design factors on flexible pavement thickness (thus, ultimately the cost of it indirectly). Secondly, the evaluation of selected designs by AASHTO'93 in the AASHTOWare enabled the quantification of benefits of the latter using some pavement 
performance criteria, as well. The numerical results and challenges of the need to adopt the $\mathrm{M}-\mathrm{E}$ approach are expected to lead the researchers and government officials to better evaluate the use of the M-E for Turkey and other developing countries.

\section{BACKGROUND}

\subsection{Flexible Pavement Design Guide by AASHTO'93}

Based on empirical findings of the AASHO Road Test at Ottawa, Illinois, USA, the first pavement design guide of 1962 was further improved in 1972 and 1986. In its latest version, AASHTO'93, it is primarily aimed to predict the layer thicknesses with limited traffic, material, and climatic data; whereas other data are taken into consideration in a limited way, for example, the climatic conditions are only taken into account for drainage and seasonal variation of the subgrade strength $[17,18]$. The major limitations of AASHTO'93 could be listed as follows $[2,3]$ :

- The design equations are based on the limited material properties, such as one subgrade type and one climatic condition. It indirectly considered the influence of the climate with resilient modulus and drainage coefficients.

- Traffic loads applications and repetitions in the equation are developed from identical axle loads and configurations and are calculated according to the Equivalent Single Axle Load (ESAL). However, increasing transportation demand and freight loads (even 10-20 times more), as well as different axle load configurations, are not met by ESAL.

- The design equations were developed in the accelerated two-year testing period, which did not address the long-term effects of climate and aging of materials. The results are extrapolated out to a longer period.

However, the AASHTO'93 guideline is still in use in $80 \%$ of states in the US [19], as well as many other countries including Turkey.

\subsection{Flexible Pavement Design by Mechanistic-Empirical (M-E) Method}

Based on the limitations discussed above, the M-E design method is developed using mechanical relations in addition to the empirical data. The distress transfer functions, mechanical part of the M-E method, are nationally calibrated using design inputs and distress data gathered in the Long-Term Pavement Program (LTPP) database [20, 21]. The M-E design method requires extensive input to better simulate the design conditions to accurately predict the distresses. Due to the availability of the inputs, hierarchical design levels are defined as Level 1, 2, and 3: Level 1 inputs are most accurate and determined through field data collection or laboratory studies. Level 2 inputs are derived from correlations and regional values. Finally, Level 3 inputs are typical local estimates, and these are the default values suggested in the M-E design guide [3].

The M-E method utilizes an elastic model as well as it works by processing various inputs (traffic, climatic and environmental conditions, material properties, reliability, subgrade types, and design layer thicknesses) to compute the pavement performance indicators [22]. 
Thus, the procedure does not directly address the thicknesses. Specifically, this method is used to evaluate a trial design for a given set of site conditions and failure criteria at a specified level of reliability [23].

The M-E design allows for better modeling of pavements and yields closer results to real conditions in life, while the AASHTO'93 guide overestimates performance for pavements especially in warm regions and at high traffic levels [24]. In the M-E design, the performance is evaluated by the cumulative incremental damage at any point in a pavement structure; and it allows for the prediction of distresses over time including International Roughness Index (IRI), rutting, fatigue, and thermal cracking in asphalt pavements, considering stress, strain and deformations based on the interactions between traffic, climate and pavement structure. The major inputs in the M-E method are discussed as follows:

\section{Climate effect in the M-E method}

The major improvement is the consideration of climatic effects on pavement materials, responses, and distresses in an integrated manner $[25,26]$. Climatic inputs are essential to predict the temperature and moisture profiles in the pavement over the design life. Pavement layer temperature and moisture predictions are calculated on an hourly basis and used to estimate the material properties for the foundation and pavement layers throughout the design life $[15,27]$. It was shown that seasonal temperature variations carry out a considerable drop in pavement durability and significantly affect the overall performance of the pavement system, which is greatly affected by temperature and moisture [8, 28]. An increase in moisture content reduces the load-carrying ability of subgrade soils. Therefore, asphalt distresses such as total rutting, fatigue and the thermal cracking of asphalt pavement highly depend on the temperature [18]. Strong relationships between peak strain values and temperature were observed in the study of Shafiee et al. [29].

AASHTOWare has an extensive number of embedded weather station data. However, these stations are only limited to airfields around the US. On the other hand, many researchers studied ways to implement the M-E design outside the US by using different methods to generate local climate inputs and to convert the data to the required format. In Jannat's study [30], climatic inputs for the M-E design method for different climate zones in Canada were determined. In another study, the monthly minimum, maximum, and average temperature values were matched with the climatic data considering annual air temperature, annual precipitation, freezing index, and the average annual number of freeze-thaw days. The similarities in average and range of seasonal temperature, percent sunshine, and wind speed were considered and compared between Italy and Alabama [6]. A weather station in Alabama was used for climatic input examined the validity of this approach by comparing locally used surface temperature equation results and climate model output. In a more recent study, virtual station matching based on climatic similarity was performed to obtain climatic data for Qatar [11]. Researchers observed the climatic conditions in Needles Airport in California, US, to be reasonably resembling the climatic conditions in Qatar. Climatic data were generated with the AASHTOWare by the interpolation of data from six nearby weather stations in Oklahoma, US [31]. In one of the latest studies to implement the M-E design in Egypt, weather-related input data were divided into subgroups based on annual temperature, annual precipitation, wind speed, relative humidity, and sunshine [28]. 


\section{Traffic conditions in the M-E method}

The M-E design method requires actual traffic data rather than a total ESAL number, which allows us to better simulate the traffic during the life of the pavement. The data briefly includes the traffic growth, axle configurations (axle spacing and wheelbase), axle load distribution factors, vehicle classification distribution, truck volume, hourly and monthly traffic volume adjustment factors, number of axles per truck and lateral traffic wander to perform analyses, in addition to standard single, tandem, tridem, and quad-axle loadings and specific percentages of each truck class [4].

\section{Subgrade effect in the M-E method}

Subgrade plays a major role in the pavement bearing capacity, which directly affects pavement performance. The variations in the properties of the soils concerning seasonal climatic conditions are taken into consideration [6,32]. As noted by Zofka et al. [7], the resilient modulus of the soil depends on the stress, moisture, and freeze-thaw cycle effects. Thus, subgrade type (soil properties) is directly affected by weather conditions and locations. On the other hand, the study of Aguib [12] showed that the change in subgrade type in AASHTO'93 do not influence the Asphalt Concrete (AC) layer thickness, since the influence of climate in this method is neglected, which is the major weakness of AASHTO'93.

\section{Reliability in the M-E method}

In the M-E design method, the reliability level is another critical criterion, which can be defined as the probability of satisfactory performance over the traffic and climate conditions for the analysis period [2]. Therefore, the M-E method yields more realistic results in the observation of reliability for rutting performance. Note: High-level reliability ultimately leads to the conservative design and tends to over-thick pavements [27].

\section{Material properties in the M-E method}

The M-E design method requires detailed material properties (e.g., aggregate gradation, air void, binder performance grade (PG), etc.). Material properties of surface course mixture are used for the climatic model, the pavement response models, and the distress models in the design process. The pavement response models need material properties considering the effects of traffic loading and temperature changes. Similarly, distress models are used to predict pavement performance $[33,34]$.

\section{Performance criteria used in the flexible design}

The performance of flexible pavements is predicted based on selected threshold values of indicators of the embedded distress models, e.g., the terminal IRI $(\mathrm{m} / \mathrm{km})$, rutting in total pavement $(\mathrm{mm}), \mathrm{AC}$ bottom-up $(\%)$, and AC top-down $(\mathrm{m} / \mathrm{km})$ fatigue cracking, AC thermal cracking $(\mathrm{m} / \mathrm{km})$ and rutting in AC only $(\mathrm{mm})$ through the design life. To optimize, the values of these indicators for various pavement thickness designs are monitored concerning the selected threshold limits. Although these threshold values may vary across agencies, the limits proposed by the AASHTO used in this study are shown in Table 1. At the beginning of the design procedure, the initial thicknesses of each layer in the software were selected according to layer thicknesses determined by the GDH based on AASHTO'93, as given in Table 2 . 
Table 1 - Flexible pavement performance criteria

\begin{tabular}{rc|c}
\hline \multicolumn{1}{r}{ Performance Criteria } & \multicolumn{1}{c}{$\begin{array}{c}\text { Limit } \\
\text { values }\end{array}$} \\
\hline Terminal IRI & $(\mathrm{m} / \mathrm{km})$ & 2.7 \\
Rutting - total pavement & $(\mathrm{mm})$ & 19.0 \\
AC bottom-up fatigue cracking & $(\%)$ & 25.0 \\
AC thermal cracking & $(\mathrm{m} / \mathrm{km})$ & 189.4 \\
AC top-down fatigue cracking & $(\mathrm{m} / \mathrm{km})$ & 378.8 \\
Rutting - AC only & $(\mathrm{mm})$ & 12.0 \\
\hline
\end{tabular}

Table 2 - Layer design thicknesses by the GDH based on AASHTO'93

\begin{tabular}{|c|c|c|c|c|c|c|c|c|c|}
\hline \multirow[b]{3}{*}{ Reliability (\%) } & \multicolumn{9}{|c|}{ AADTT* } \\
\hline & \multicolumn{3}{|c|}{1000} & \multicolumn{3}{|c|}{7500} & \multicolumn{3}{|c|}{15000} \\
\hline & 85 & 90 & 95 & 85 & 90 & 95 & 85 & 90 & 95 \\
\hline & \multicolumn{9}{|c|}{ Pavement Layer Thickness (cm) } \\
\hline Surface course & 5 & 5 & 5 & 5 & 5 & 5 & 5 & 5 & 5 \\
\hline Binder course & 6 & 6 & 6 & 7 & 8 & 8 & 8 & 10 & 10 \\
\hline Bituminous base & 8 & 8 & 8 & 10 & 11 & 11 & 11 & 12 & 12 \\
\hline Base course & 15 & 20 & 20 & 20 & 20 & 20 & 20 & 20 & 20 \\
\hline Subbase course $* *$ & 20 & 20 & 20 & 20 & 20 & 20 & 20 & 20 & 20 \\
\hline
\end{tabular}

\section{METHODOLOGY}

\subsection{Determination of Climatic Regions for the M-E Pavement Design in Turkey}

There are limited number of studies in Turkey on the M-E design. In the Izmir (city in Turkey) study [15], the focus was the data collection to implement the M-E design, but no runs were performed. In the only study performing the M-E based rigid pavement designs [16], 8 cities were studied individually by simply matching them with the selected US city/weather stations.

In this study, a more general evaluation was made by dividing the country into the climatic regions (CLs) based on Bitumen Class Selection Maps [35] respecting climatic characteristics. Accordingly, 81 provinces of Turkey were divided into 8 CLs as shown in Table 3. This suggested that many cities could be grouped in a single CL from the point of flexible pavement design based on the PG binder selection. It should be also noted that these CLs almost overlapped with climate regions from the Köppen-Geiger Climate Classification Map of Turkey (see Figure 1). For example, regions having hot-summer-Mediterranean climatic conditions based on Köppen-Geiger climate type exhibited similar conditions to climate characteristics of Izmir (Mediterranean/warm). 
Table 3 - CLs classification table for Turkey

\begin{tabular}{|c|c|c|}
\hline CL* & Share $(\%)$ & Provinces (81) \\
\hline 1 & 13.11 & Antalya; Aydin; Balikesir; Denizli; Elazig; Izmir; Manisa; Mugla; \\
\hline 2 & 13.48 & Agri; Bolu; Erzurum; Kars; Sivas; Yozgat; Bayburt; Ardahan; \\
\hline 3 & 7.36 & $\begin{array}{l}\text { Giresun; Istanbul; Ordu; Rize; Sakarya; Samsun; Sinop; Tekirdag; } \\
\text { Trabzon; Zonguldak; Yalova; }\end{array}$ \\
\hline 4 & 16.14 & $\begin{array}{l}\text { Afyonkarahisar; Artvin; Bilecik; Bitlis; Cankiri; Gumushane; } \\
\text { Kastamonu; Kayseri; Kutahya; Nevsehir; Nigde; Van; Duzce; }\end{array}$ \\
\hline 5 & 19.87 & $\begin{array}{l}\text { Adana; Ankara; Erzincan; Isparta; Kirklareli; Kirsehir; Konya; } \\
\text { Tokat; Usak; Aksaray; Karaman; Kirikkale; Karabuk; }\end{array}$ \\
\hline 6 & 15.25 & $\begin{array}{l}\text { Amasya; Bingol; Burdur; Bursa; Canakkale; Corum; Edirne; } \\
\text { Eskisehir; Hakkari; Kocaeli; Malatya; Mus; Tunceli; Bartin; Igdir; }\end{array}$ \\
\hline 7 & 7.78 & Adiyaman; Diyarbakir; Mardin; Siirt; Sanliurfa; Batman; \\
\hline 8 & 7.01 & $\begin{array}{l}\text { Gaziantep; Hatay; Mersin; Kahramanmaras; Sirnak; Kilis; } \\
\text { Osmaniye; }\end{array}$ \\
\hline
\end{tabular}

* CL stands for the climatic region
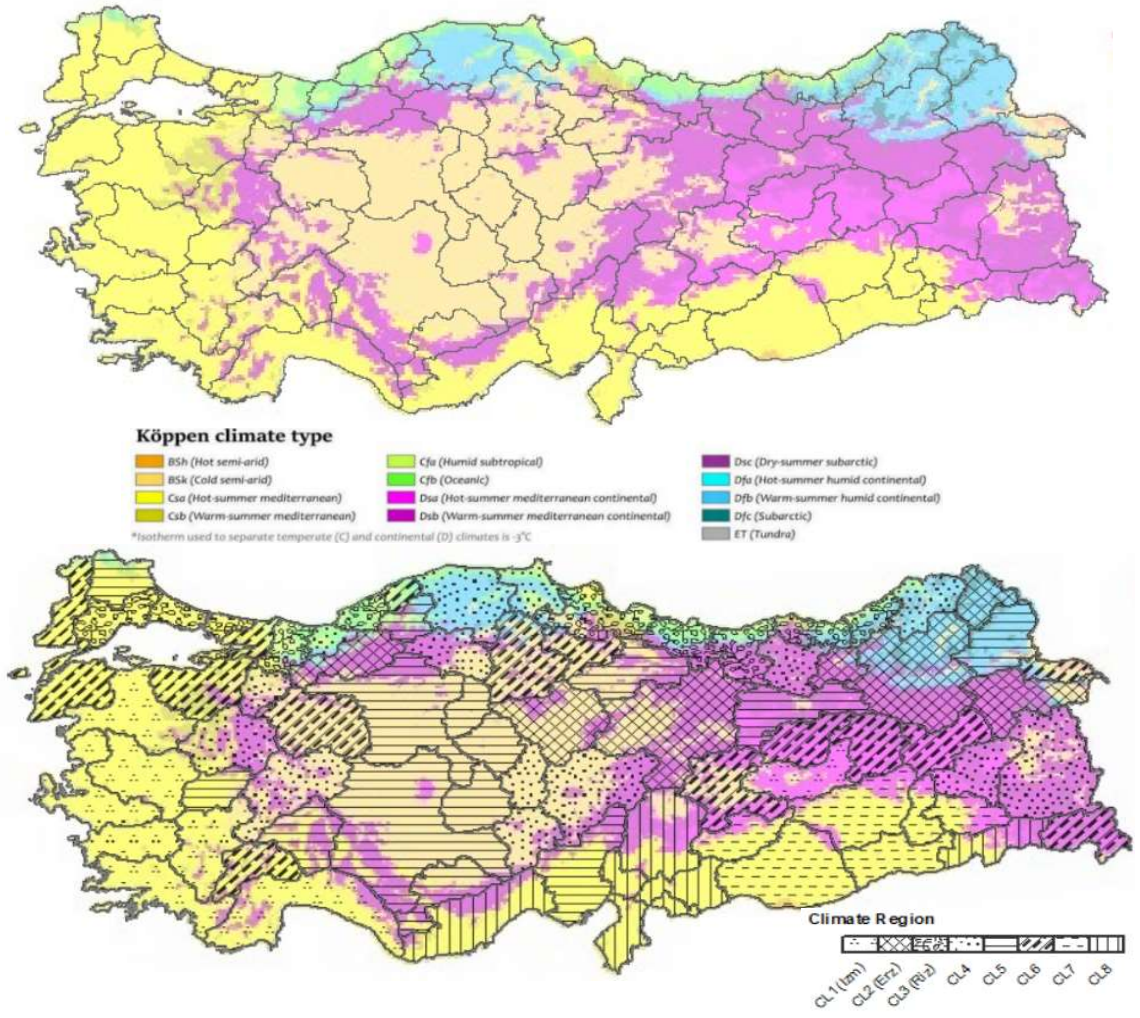

Figure 1 - Recommended climate regions for Turkey (adopted from Köppen-Geiger Climate Classification Map for Turkey) [40] 
Due to data and time limitations, in this study, the M-E pavement design is performed for CL1 (Izmir-Izm), CL2 (Erzurum-Erz), and CL3 (Rize-Riz) climatic conditions, respectively, and the results of which can be generalized for $33.95 \%$ of Turkey by coverage area.

\subsection{Factor Analysis Approach Using M-E Pavement Design Process}

The M-E design process requires the design input parameters as well as performance criteria, as presented in Figure 2. The performance outputs include information on stresses, strains, and deformations that are directly converted to the performance criteria. If the outputs are within the acceptable threshold limits (see Table 1), the M-E design is finalized; if not, the evaluated trial design is modified to re-run, in other words, more iterations are done. Among the acceptable designs obtained by trial designs, the design that matches the performance criteria limits with the closest values was defined as the "optimized M-E design".

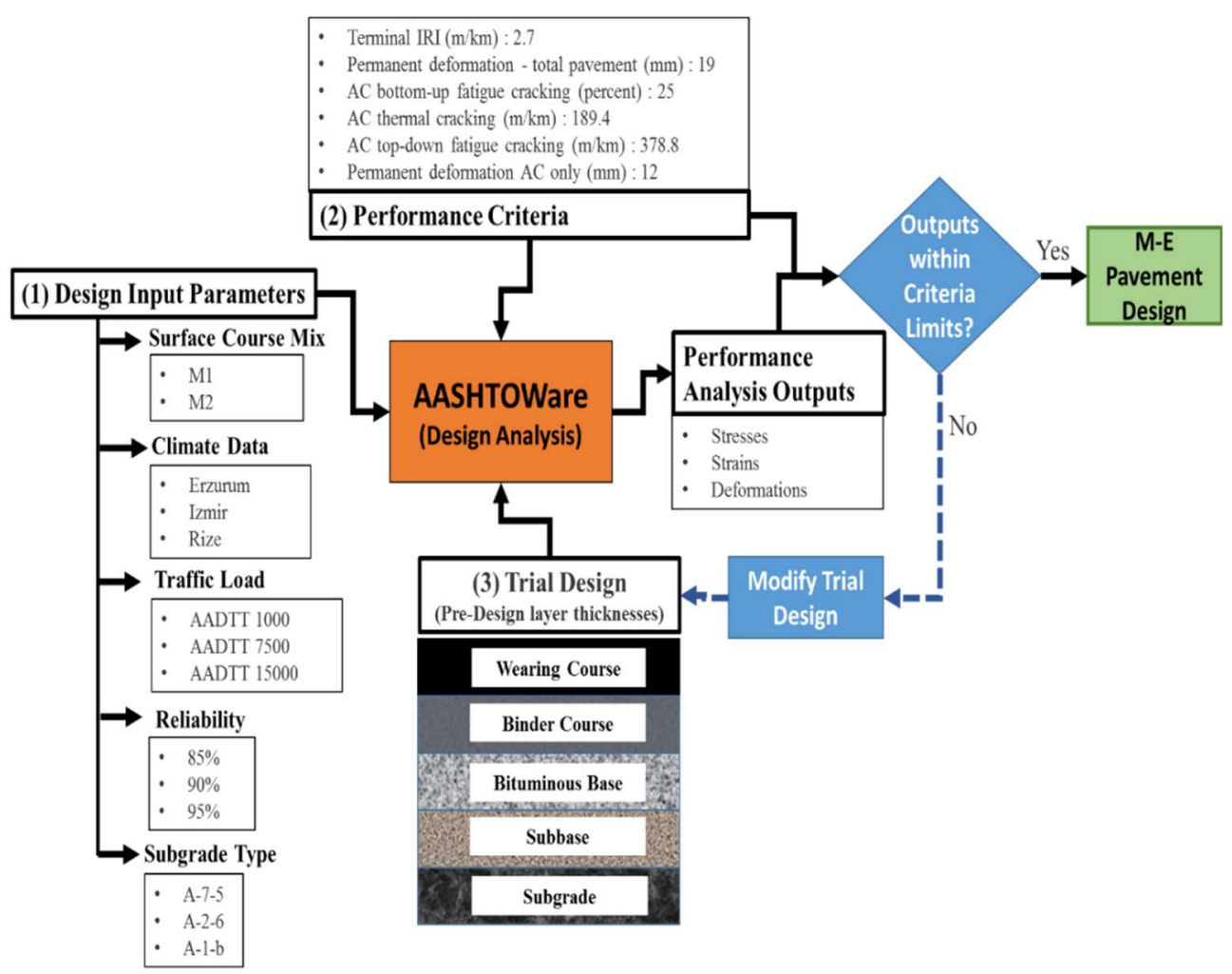

Figure 2 - M-E design process with selected input and performance criteria sets in this study 


\subsection{Selection of Design Input Parameters}

The study investigated the effect of 5 design input parameters as follows:

- Climatic data: Izmir (warm/Mediterranean), Erzurum (cold) and Rize (rainy).

- Traffic load: Truck traffic volumes of AADTT-1000 (low), AADTT-7500 (medium), and AADTT-15000 (high).

- Surface course mixture gradation and asphalt cement: Mix designs of Mix 1 (M1coarser) and Mix 2 (M2-finer). Note: The asphalt cement selection depends on the climate and traffic load.

- $\quad$ Subgrade type: clayey-silty soil (A-7-5), sandy pebble granular soil (A-2-6), rocky soil $(\mathrm{A}-1-\mathrm{b})$ and one subbase type $(\mathrm{A}-1-\mathrm{a})$.

- Reliability levels: $85 \%, 90 \%$, and $95 \%$ selected to show the performance of the road quality (service level).

In this approach, evaluation is based on a total of 162 input design parameter sets composed of " 3 climate regions x 3 traffic loads x 3 subgrade types x 3 reliability levels x 2 mix designs". For each set, several M-E designs were generated based on the assumed trial designs. The resulting acceptable M-E designs were later reviewed to analyze the impact of the selected design parameters and discussed below in further detail.

\subsubsection{Determination of Climatic Regions in Turkey}

The effect of the climate on the pavement design depends on the climatic inputs, which can affect the amount of heat transfer at the surface of the asphalt pavement, pavement layer

Table 4 - Climate data for the study regions [16]

\begin{tabular}{|c|c|c|c|c|}
\hline \multicolumn{2}{|l|}{ Climate Data } & Izmir & Erzurum & Rize \\
\hline \multicolumn{5}{|c|}{ Annual Average Temperatures } \\
\hline Winter-minimum & $\left({ }^{0} C\right)$ & 6.60 & -12 & 4.20 \\
\hline Summer-maximum & $\left({ }^{\circ} \mathrm{C}\right)$ & 32.30 & 29.00 & 25.43 \\
\hline Spring & $\left({ }^{0} C\right)$ & 16.30 & 11.10 & 11.90 \\
\hline Autumn & $\left({ }^{0} C\right)$ & 18.80 & 12.90 & 15.90 \\
\hline Annual average & $\left({ }^{\circ} C\right)$ & 17.90 & 12.01 & 14.30 \\
\hline Annual precipitation & $(\mathrm{mm})$ & 690.30 & 402.20 & 2245.30 \\
\hline Elevation & $(m)$ & 30.0 & 1853.0 & 6.0 \\
\hline Wind speed & $(\mathrm{m} / \mathrm{s})$ & 6.00 & 5.00 & 4.00 \\
\hline Moisture & $(\%)$ & 70 & 65 & 75 \\
\hline $\begin{array}{l}\text { Daily avg. solar } \\
\text { radiation }\end{array}$ & $\left(\mathrm{kWh} / \mathrm{m}^{2}\right)$ & 4.30 & 4.00 & 4.00 \\
\hline \multicolumn{2}{|c|}{ Matched US Weather Stations } & $\begin{array}{c}\text { Marysville Int. } \\
\text { Airport, CA }\end{array}$ & $\begin{array}{l}\text { Soda Springs Int. } \\
\text { Airport, Idaho } \\
\text { Falls-ID }\end{array}$ & $\begin{array}{c}\text { Crescent City, } \\
\text { CA }\end{array}$ \\
\hline
\end{tabular}


temperatures, and moisture conditions. The M-E method requires detailed inputs including annual air temperature $\left({ }^{\circ} \mathrm{C}\right)$, annual precipitation $(\mathrm{mm})$, wind speed $(\mathrm{km} / \mathrm{h})$, sunshine $(\%)$, cloud cover, relative humidity $(\%)$, and hourly air temperature distribution by month as well as the depth of groundwater table to properly calculate the temperature and moisture profile of a pavement section to predict the distresses. This detailed level of climatic data is significantly costly to provide in Turkey. Therefore, the climates of the study regions were matched with weather stations in the US. This approach has been used by many researchers implementing AASHTOWare outside the US [8, 14, 18, 28, 36]. For this purpose, annual average data for minimum winter and maximum summer temperatures, spring and autumn temperatures, average temperature, average precipitation, elevation, wind, and solar radiation were collected for three study regions and matched with the US weather stations as shown in Table 4 and Figure 3.

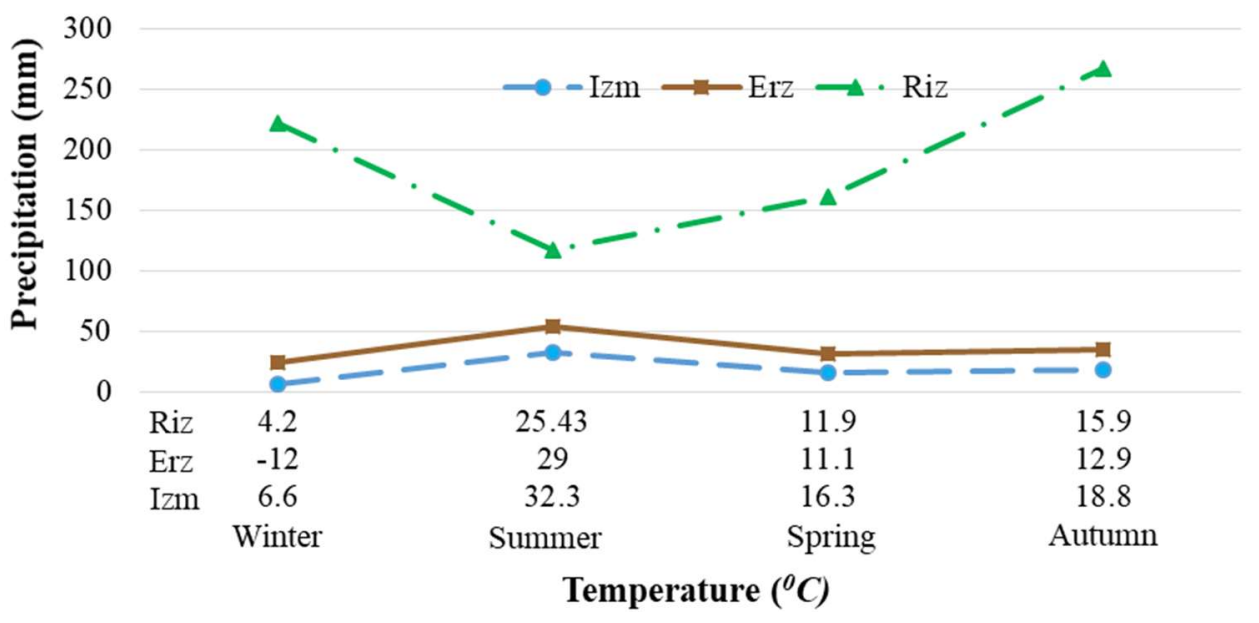

Figure 3 - Seasonal precipitation versus temperature data for the study locations [37]

\subsubsection{Selection of Traffic Conditions}

Three different AADTT values were selected considering different truck traffic in Turkey for each study region. These values were within the observed AADTT values, which range from 2800 to 37000 heavy vehicles on the Turkish Motorway network [38]. For traffic load calculations, the growth rate was fixed at $2 \%$ due to a drastic increase in the traffic volume in Turkey [39]. AASHTOWare requires detailed information on axle loads, configurations, and daily, monthly and seasonal changes in traffic volume. However, this information was not available at the time of this study, therefore default values of the software were used. Besides, vehicle class distributions were also assumed to be constant over the years. 


\subsubsection{Selection of Surface Course Mix Design}

According to the specifications of the GDH, the following asphalt PG classes were selected based on the location and AADTT as shown in Figure 4. For the surface course, the GDH recommends majorly two different types of mixtures (M1 and M2) based on the aggregate gradation. M1 is a finer mix than M2. Job mix formulas used in this study were selected among various field applications. Eventually, two types of mixtures were determined according to their gradation limits; designated as M1 and M2 as shown in Table 5 and Figure 5.
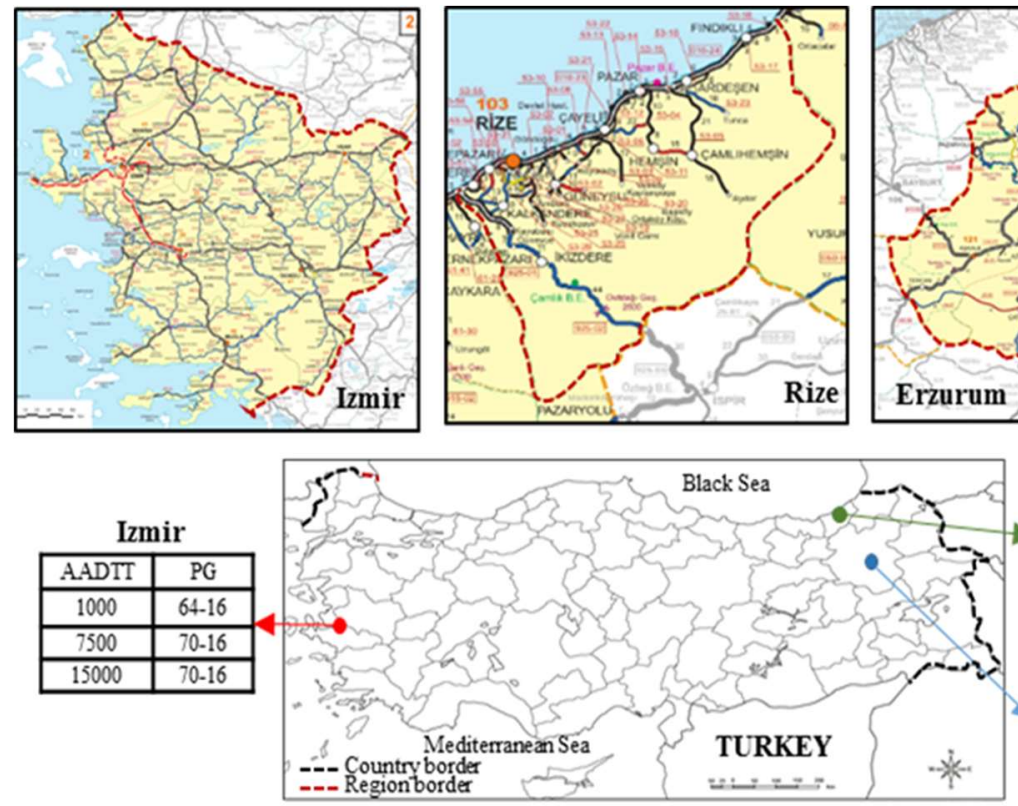

Figure 4 - PG class by AADTT for each study region (adopted from [35])

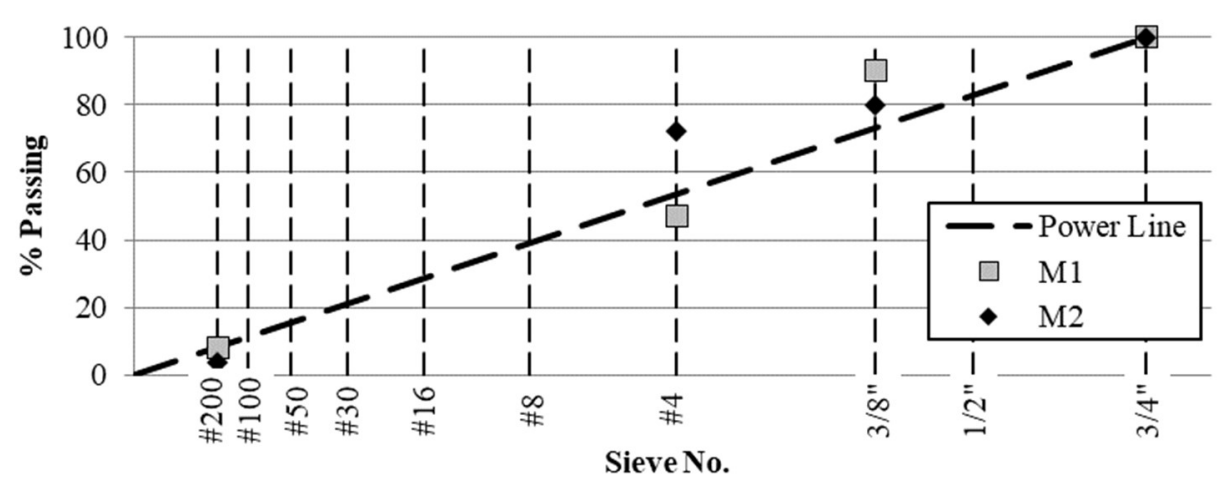

Figure 5 - Surface course mixture gradation limits

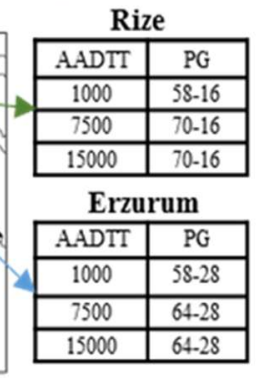

\begin{tabular}{|c|c|}
\hline AADTT & PG \\
\hline 1000 & $58-28$ \\
\hline 7500 & $64-28$ \\
\hline 15000 & $64-28$ \\
\hline
\end{tabular}

\section{Erzurum}


Table 5 - Mix properties for the surface course

\begin{tabular}{rcc}
\hline \multicolumn{1}{c}{ Mixture Properties } & M1 & M2 \\
\hline $3 / 4$ in \% & 100.0 & 100.0 \\
$3 / 8$ in \% & 90.0 & 80.0 \\
$\# 4 \%$ & 47.0 & 72.0 \\
$\# 200 \%$ & 8.0 & 4.0 \\
$\mathrm{~V}_{\mathrm{h}}($ Void ratio \%) & 3.0 & 5.0 \\
$\mathrm{~V}_{\mathrm{b}}$ (Bitumen amount \%) & 11.5 & 14.0 \\
\hline
\end{tabular}

\subsubsection{Determination of Subgrade and Base Types}

To define soil properties, the soil classification system developed by the AASHTO for pavement applications was used to determine the effect of subgrade type and granular base thickness on the M-E flexible pavement design. To observe the effect of the subgrade type on design, three types were specified for each region as follows:

- A-7-5 representing high plasticity clayey-silty soils,

- A-2-6 representing normal-strength sandy pebble granular soils,

- A-1-b representing rocky soils with high carrying capacity values.

Besides, A-1-a (non-stabilized) was selected as the base layer type, since it is the common practice in Turkey. It includes Level 3 inputs such as Poisson's ratio (0.35), coefficient of lateral earth pressure $(0.5)$, maximum dry unit weight $\left(2038.2 \mathrm{kgf} / \mathrm{m}^{3}\right)$, saturated hydraulic conductivity $(1.54 \mathrm{e}-\mathbf{0 2} \mathrm{m} / \mathrm{hr})$, the specific gravity of solids $(2.7)$, optimum gravimetric water content (7.4\%) and resilient modulus $(275.8 \mathrm{psi})$.

\subsubsection{Determination of reliability}

Reliability shows the probability of whether the predicted performance indicator of the trial design satisfies the design criteria [2]. In this study, to observe the reliability effect on the pavement, three reliability levels (i.e., secondary, interstate, and intercity roads) were chosen as $85 \%, 90 \%$, and $95 \%$, respectively.

\subsection{Performance evaluations}

To show the performance of the M-E method and the difference between the M-E and AASHTO'93, both the performance indicators and the effects of the parameters are presented in Table 6, which includes each comparison. The "Given" column refers to parameters that are fixed in the software and the last two columns include parameters and performance indicators that are analyzed to determine their effects on pavement performance. Each comparison is discussed in Section 4 in detail. 
Table 6 - Comparison scenarios of the study

\begin{tabular}{l|l|l|c}
\hline \multicolumn{1}{c|}{ Comparisons } & \multicolumn{1}{|c|}{ Given } & \multicolumn{1}{|c|}{ Parameters } & Indicators \\
\hline Comp 1 (see Table 7) & T, S & C, R, M, LT & \\
\hline Comp 2 (see Table 8) & S, M, R & T, C, LT & TR \\
\hline Comp 3 (see Table 9) & T, M, R & S, C, LT & IRI \\
\hline Comp 4 (see Table 7) & T, S, M & C, R, LT & FC \\
\hline Comp 5 (see Table 10) & T, S & C, R, M, LT & \\
\hline
\end{tabular}

1) $T, C, S, M$, and $R$ stand for traffic volume, climate, subgrade, surface course mix design, and reliability, respectively.

2) LT, TR, IRI, and FC stand for layer thicknesses, total rutting, International Roughness Index, and fatigue cracking, respectively.

\section{NUMERICAL RESULTS}

To evaluate and compare the optimized designs, total pavement rutting was considered as the first indicator throughout the study, since TR was found to be the most dominant distress acting on pavements $[6,12,18]$. Secondly, the IRI and FC were investigated as the critical parameters $[12,31,41]$. It should be noted that IRI was also a function of other distresses in pavements $[42,43]$. The designs were being carried out based on economy and safety by approaching the nearest level of threshold values of the three performance criteria through an iterative process. Overall, 162 designs were optimized based on limiting performance indicators. In the following subsections, various factors were discussed separately.

\subsection{Climate Effect}

To observe the climate effect on flexible pavement design, results obtained from the three regions having different climatic conditions were analyzed by keeping the other aforementioned inputs the same. The results revealed that the climate effect is the main parameter influencing the pavement performance. As shown in Table 7, CL3(Riz) had equal or smaller pavement layer thicknesses compared with other regions under the same conditions, since CL3 has the least seasonal temperature change. On the other hand, drainage conditions in CL3(Riz) was assumed to be well-drained; however, in future studies, drainage should be considered more precisely. It should be noted that the PG classes for each region were different from each other. On the other hand, the FC results of CL3(Riz) were higher than both CL1(Izm) and CL2(Erz), because of the thinner sections. As the reliability level increases, cracking increases in general. In this case, $\mathrm{FC}$ was affected by colder climates with low temperatures and high precipitation rather than warmer temperatures or the reliability level. Thus, to maintain similar levels of FC, layer thicknesses should be varied highly between climatic regions. Moreover, it should be noted that IRI and rutting are also affected by climatic differences. 
Table 7 - Climate effect on layer thicknesses (for 20-year service life) (Given: AADTT7500; Subgrade $=A-1-b$ )

\begin{tabular}{|c|c|c|c|c|c|c|c|c|c|}
\hline CL & \multicolumn{3}{|c|}{ CL1(Izm) } & \multicolumn{3}{|c|}{ CL2(Erz) } & \multicolumn{3}{|c|}{ CL3(Riz) } \\
\hline Reliability & $85 \%$ & $90 \%$ & $95 \%$ & $85 \%$ & $90 \%$ & $95 \%$ & $85 \%$ & $90 \%$ & $95 \%$ \\
\hline & \multicolumn{9}{|c|}{ M1 } \\
\hline Binder & 14 & 14 & 14 & 10 & 10 & 11 & 5 & 5 & 6 \\
\hline $\begin{array}{r}\text { Bituminous } \\
\text { Base }\end{array}$ & 15 & 15 & 16 & 15 & 15 & 15 & 7 & 8 & 8 \\
\hline Subbase & 20 & 20 & 20 & 20 & 20 & 20 & 10 & 10 & 10 \\
\hline TR & 16.65 & 17.37 & 17.11 & 17.22 & 17.95 & 18.65 & 13.85 & 14.22 & 15.13 \\
\hline IRI & 2.14 & 2.25 & 2.38 & 2.26 & 2.38 & 2.55 & 2.12 & 2.22 & 2.37 \\
\hline \multirow[t]{2}{*}{ FC } & 1.28 & 1.56 & 1.95 & 1.36 & 1.64 & 2.01 & 16.41 & 12.28 & 6.44 \\
\hline & \multicolumn{9}{|c|}{ M2 } \\
\hline Binder & 12 & 12 & 12 & 10 & 10 & 12 & 5 & 5 & 6 \\
\hline $\begin{array}{r}\text { Bituminous } \\
\text { Base }\end{array}$ & 16 & 18 & 18 & 15 & 15 & 15 & 7 & 8 & 8 \\
\hline Subbase & 20 & 20 & 20 & 20 & 20 & 20 & 10 & 10 & 10 \\
\hline TR & 17.99 & 16.25 & 17.25 & 17.48 & 18.21 & 17.11 & 14.09 & 14.47 & 15.4 \\
\hline IRI & 2.17 & 2.22 & 2.39 & 2.27 & 2.39 & 2.52 & 2.13 & 2.22 & 2.36 \\
\hline FC & 1.31 & 1.54 & 1.95 & 1.36 & 1.64 & 1.99 & 16.76 & 13.24 & 7.04 \\
\hline
\end{tabular}

Note: i) Layer thickness values in cm. TR in $\mathrm{mm}$. IRI in $(\mathrm{m} / \mathrm{km})$. FC in \%. ii) Surface course thickness was kept constant at $5 \mathrm{~cm}$ for all analyses since, in typical construction practice, $5 \mathrm{~cm}$ thickness is constant according to the GDH practice. iii) These notes are acceptable for all the following tables.

\subsection{Traffic Effect}

According to Table 8, the results indicated that under low traffic (AADTT-1000), layer thicknesses (Binder-Bituminous Base-Subbase) were found to be (6-7-10) for CL1(Izm), (56-15) for CL2(Erz) and (4-5-10) CL3(Riz). These estimated values were thinner than those of the standard application (6-8-20) in Turkey for $90 \%$ reliability level (Table 2). Comparisons of designs in terms of layer thickness based on traffic volume were also given in scaled cross-sections (see Figure 6). In this case, the M-E method indicated an economic design over the AASHTO'93 (typical application) under low traffic.

To compare the regions for climatic conditions only might be misleading, since the PG selection is based on both the climate and traffic load. PG of AC is the same for traffic load levels of 7500 and 15000 in each region (Figure 4). Therefore, results are evaluated for each region, separately. The layer thicknesses increase with the increase in traffic load. Current AASHTO'93 practice for AADTT-7500 (8-11-20) and AADTT-15000 (10-12-20) requires thinner thickness than M-E results for CL2(Erz) and CL1(Izm), but results for 
Table 8 - Traffic effect on layer thicknesses (for 20-year service life) (Given: Subgrade = $A-1-b ;$ Mix design $=M 1 ; R=90 \%$ )

\begin{tabular}{r|ccc|ccc|ccc|}
\cline { 2 - 10 } CL & \multicolumn{3}{|c|}{ CL1(Izm) } & \multicolumn{3}{c|}{ CL2(Erz) } & \multicolumn{3}{c|}{ CL3(Riz) } \\
\hline AADTT & $\mathbf{1 0 0 0}$ & $\mathbf{7 5 0 0}$ & $\mathbf{1 5 0 0 0}$ & $\mathbf{1 0 0 0}$ & $\mathbf{7 5 0 0}$ & $\mathbf{1 5 0 0 0}$ & $\mathbf{1 0 0 0}$ & $\mathbf{7 5 0 0}$ & $\mathbf{1 5 0 0 0}$ \\
\hline Binder & 6 & 14 & 15 & 5 & 10 & 11 & 4 & 5 & 6 \\
Bituminous & 7 & 15 & 18 & 6 & 15 & 18 & 5 & 8 & 8 \\
Base & & & & & & & & & \\
Subbase & 10 & 20 & 20 & 15 & 20 & 20 & 10 & 10 & 10 \\
TR & 16.53 & 17.37 & 18.93 & 14.97 & 17.95 & 18.62 & 10.62 & 14.22 & 17.27 \\
IRI & 2.24 & 2.25 & 2.29 & 2.32 & 2.38 & 2.4 & 2.11 & 2.22 & 2.31 \\
FC & 2.17 & 1.56 & 1.57 & 2.46 & 1.64 & 1.64 & 3.44 & 12.28 & 20.64 \\
\cline { 2 - 9 }
\end{tabular}

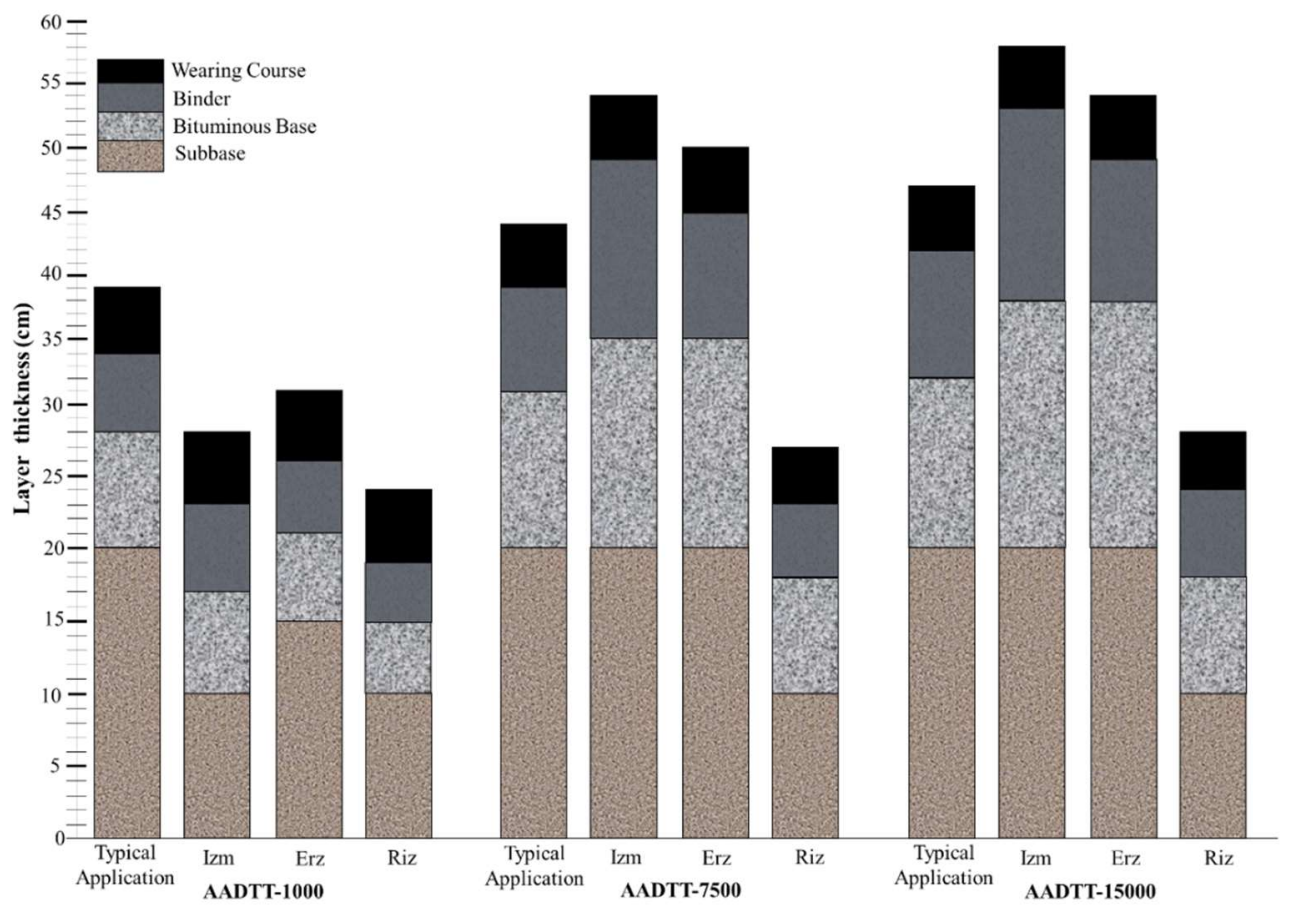

Figure 6 - Visual depiction of the typical and M-E designs for selected traffic volumes $(R=90 \%)$ 
CL3(Riz) were significantly thinner than current practice in Turkey. Therefore, the current practice may under-design the layer thicknesses as required regarding warmer and cold climatic conditions. The IRI is not significantly varied between the optimized designs under different traffic loads, whereas the TR considerably increases under different traffic loads (see Table 8). It can be concluded that both IRI and FC are affected by the traffic loading. It should be noted that traffic loading dominates rutting more. In CL1(Izm) and CL2(Erz), to keep the distresses around the same level under different traffic loads, the layer thicknesses should be increased. Only a slight increase is observed for the CL3(Riz) case. Since there is little variation in seasonal temperatures, the significant precipitation influence is eliminated by choosing good drainage conditions. Therefore, after local calibrations, the precipitation should be separately taken into consideration.

\subsection{Subgrade Effect}

To study the effect of subgrade, M-E designs with low traffic (AADTT-1000), coarser surface course (M1) and 85\% reliability level were analyzed for three subgrade types (low strength A-7-5, medium-strength A-2-6, and high strength A-1-b) as shown in Table 9. The optimized designs indicated that subgrade type and its strength have significant impact on the flexible pavement performance, as expected. In the CL2(Erz) case, layer thicknesses were selected as (3-5-15) for all subgrade types, respectively. However, the A-7-5 subgrade yielded higher rutting and the A-1-b created a lower deformation due to its high strength with a high modulus. Similar results were obtained for CL1(Izm) and CL3(Riz), although the thicknesses of bituminous bases were decreased by $1 \mathrm{~cm}$ and $2 \mathrm{~cm}$, respectively.

Table 9 - Subgrade type effect on layer thicknesses (for 20-year service life) (Given: AADTT-1000; Mix design $=M 1 ; R=85 \%$ )

\begin{tabular}{r|ccc|ccc|ccc|}
\cline { 2 - 10 } CL & \multicolumn{3}{|c|}{ CL1(Izm) } & \multicolumn{3}{c|}{ CL2(Erz) } & \multicolumn{3}{c|}{ CL3(Riz) } \\
\hline Subgrade & A-7- & A-2- & A-1- & A-7- & A-2- & A-1- & A-7- & A-2- & A-1- \\
Type & $\mathbf{5}$ & $\mathbf{6}$ & $\mathbf{b}$ & $\mathbf{5}$ & $\mathbf{6}$ & $\mathbf{b}$ & $\mathbf{5}$ & $\mathbf{6}$ & b \\
\hline Binder & 4 & 4 & 4 & 3 & 3 & 3 & 3 & 3 & 3 \\
Bituminous & 7 & 7 & 6 & 5 & 5 & 5 & 5 & 5 & 3 \\
Base & & & & & & & & & \\
Subbase & 10 & 10 & 10 & 15 & 15 & 15 & 10 & 10 & 10 \\
TR & 17.61 & 17.80 & 16.24 & 16.94 & 17.15 & 15.13 & 13.63 & 13.46 & 11.33 \\
IRI & 2.32 & 2.27 & 2.15 & 2.42 & 2.37 & 2.24 & 2.24 & 2.18 & 2.07 \\
FC & 16.52 & 10.26 & 6.34 & 18.57 & 17.06 & 12.87 & 18.65 & 16.81 & 18.46 \\
\hline
\end{tabular}

Designs conceived for CL1(Izm) had (4-7-10) layer thicknesses for A-7-5 and A-2-6, but A1-b required thickness values of (4-6-10). Similarly, designs for CL3(Riz) involved (3-5-10) layer thicknesses for A-7-5 and A-2-6 subgrades, but A-1-b required thickness values of (3$3-10)$. In other words, subgrades with high strength required thinner layers. Also, the M-E 
trial designs required thinner layers than typical application thicknesses in Turkey (Table 2). This also reveals the importance of calibration.

The IRI and FC exhibited a descending trend depending on the increased loading capacity of subgrades. A-1-b results generated the least cracking except for CL3 (Riz), which might be due to the drainage factor assumed to be well-drained. Although the results of the A-7-5 subgrade for CL2(Erz) indicated similar findings with CL1(Izm) concerning deformations, the IRI and FC in CL1(Izm) were smaller due to the differences in climatic conditions.

\subsection{Reliability Effect}

To analyze the reliability, a subset of the designs for medium traffic (AADTT-7500), coarser surface course (M1), and high strength subgrade (A-1-b) were examined as given in Table 7. Accordingly, the CL2(Erz) case had almost the same layer thicknesses of (10-15-20) for all reliability levels (for $95 \%$ level, the binder layer thickness is increased by $1 \mathrm{~cm}$ ). Similarly, for CL1(Izm), layer thicknesses were estimated around (14-15-20) for values of the all reliability levels (at a 95\% level, the bituminous base thickness was needed to be increased by $1 \mathrm{~cm}$ due to greater deformations). In CL3(Riz), layer thicknesses were estimated as (5$7-10$ ) for $85 \%$ reliability level, the bituminous base needed an additional $1 \mathrm{~cm}$ thickness for $90 \%$ level, while at $95 \%$ level, the layer thicknesses of both binder and bituminous base were increased by $1 \mathrm{~cm}$. However, in three climatic regions, greater deformations were observed at increased reliability levels.

On the other hand, the selected PG classes in Turkey in the standard application were different for all regions (See Figure 4). In terms of predicted IRI and FC, an ascending trend was found in all regions depending on the reliability level. Consequently, increases in reliability levels, i.e. road quality, resulted in increases in layer thickness values. However, findings for CL3(Riz) showed reverse results than other cities considering FC distresses, probably due to a significant increase in thickness.

\subsection{Surface Course Mix Design Effect}

To analyze mix design effect, low traffic (AADTT-1000), subgrade type A-2-6 for granular soil with medium strength, and three reliability levels $(85 \%, 90 \%$, and $95 \%)$ during 20 -year service life were re-tabulated for each region in Table 10. Results of the selected two mix designs (M1-coarser and M2-finer) showed that for CL2(Erz) and CL1(Izm), layer thicknesses under the same conditions were almost the same (or slightly thicker with $1 \mathrm{~cm}$ difference for bituminous base). For example, in CL2(Erz), while the mix M1 required (3-515) thickness values, M2 required (3-6-15) for $85 \%$ reliability. Moreover, in $95 \%$ reliability, the M2 combination sometimes needs a greater thickness of about an increase of $3 \mathrm{~cm}$. As the reliability level increases, the deformations arising from M1 and M2 increase, and the lower strength material led to lower performance. Typically, the mixture with finer gradation corresponds to higher rutting and requires thicker layers. Moreover, the surface course design significantly affects FC. For the cases with the same reliability level and layer thicknesses, the surface mix design change from coarser to finer leads to an increase in cracking. On the other hand, IRI increases based on the reliability level independent of the layer thickness increase. However, for the cases with the same reliability level and layer thicknesses, no considerable change is observed. 
Table 10 - Surface mix design and reliability effect on layer thicknesses (for 20-year service life) (Given: AADTT-1000; Subgrade = A-2-6)

\begin{tabular}{|c|c|c|c|c|c|c|}
\hline \multirow{2}{*}{$\begin{array}{r}\text { Reliability } \\
\text { Surface Course Material }\end{array}$} & \multicolumn{2}{|c|}{$85 \%$} & \multicolumn{2}{|c|}{$90 \%$} & \multicolumn{2}{|c|}{$95 \%$} \\
\hline & M1 & M2 & M1 & M2 & M1 & M2 \\
\hline & \multicolumn{6}{|c|}{ CL1(Izm) } \\
\hline Binder & 4 & 4 & 5 & 5 & 5 & 5 \\
\hline Bituminous Base & 6 & 6 & 6 & 6 & 7 & 8 \\
\hline Sub-Base & 15 & 15 & 15 & 15 & 15 & 15 \\
\hline TR & 18.38 & 18.48 & 18.87 & 18.67 & 18.99 & 19.07 \\
\hline IRI & 2.28 & 2.29 & 2.38 & 2.38 & 2.54 & 2.53 \\
\hline \multirow[t]{2}{*}{ FC } & 10.81 & 11.34 & 5.4 & 5.81 & 3.47 & 2.85 \\
\hline & \multicolumn{6}{|c|}{ CL2(Erz) } \\
\hline Binder & 3 & 3 & 3 & 3 & 5 & 5 \\
\hline Bituminous Base & 5 & 6 & 5 & 6 & 6 & 7 \\
\hline Sub-Base & 15 & 15 & 15 & 15 & 15 & 15 \\
\hline TR & 17.15 & 17.3 & 17.76 & 17.92 & 17.68 & 17.24 \\
\hline IRI & 2.37 & 2.37 & 2.37 & 2.49 & 2.63 & 2.61 \\
\hline \multirow[t]{2}{*}{ FC } & 17.06 & 14.41 & 20.38 & 17.24 & 4.28 & 3.00 \\
\hline & \multicolumn{6}{|c|}{ CL3(Riz) } \\
\hline Binder & 3 & 3 & 3 & 3 & 3 & 4 \\
\hline Bituminous Base & 5 & 5 & 5 & 6 & 5 & 7 \\
\hline Sub-Base & 10 & 10 & 10 & 10 & 10 & 10 \\
\hline TR & 13.46 & 13.57 & 13.96 & 13.86 & 14.71 & 13.64 \\
\hline IRI & 2.18 & 2.19 & 2.30 & 2.29 & 2.47 & 2.41 \\
\hline FC & 16.81 & 17.05 & 20.09 & 15.90 & 24.96 & 3.34 \\
\hline
\end{tabular}

\subsection{Supplementary Economic Analysis for Different Traffic Volumes}

In order to discuss the economic impacts of the use of M-E method, a comparative cost table for selected cities is prepared based on the thicknesses predicted for different traffic volumes at $90 \%$ reliability. However, it should be re-noted that the economic analysis presented herein is based on the thicknesses predicted without regional calibration of the AASHTOWare. Therefore, the findings may contain some uncertainty. The cost calculation is implemented based on $1 \mathrm{~km}$ of 2 lane highway segment having a lane width of $3.5 \mathrm{~m}$ and a shoulder width of $0.5 \mathrm{~m}$. The item numbers representing the unit price (TL) of the layers belong to the GDH and were published in 2020 [44]. Upon these unit prices, the cost per $1 \mathrm{~cm}$ thickness per layer was calculated to estimate the price of the overall $1 \mathrm{~km}$ section as given in Table 11. While M-E designs cost less at low traffic volume, the cost increases slightly as the tr affic load increases, requiring thicker layers in CL1(Izm) and CL2(Erz). On the other hand, CL3(Riz) costs less with thinner layers under all traffic volumes. However, it should be reminded that the effect of the drainage is neglected from the analysis. 


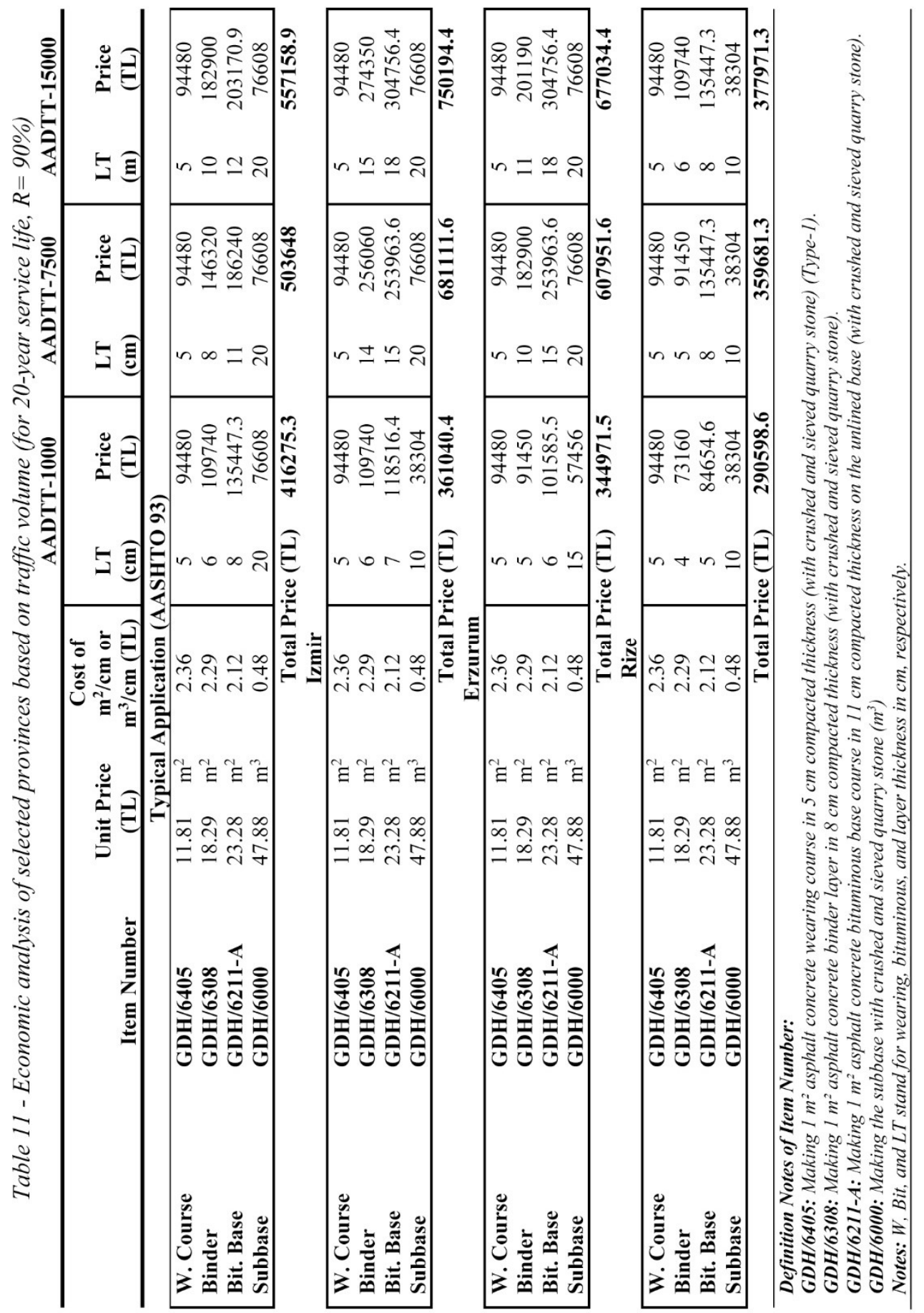


For example, for AADTT-7500 in Erzurum (10-15-20), standard application of AASHTO'93 costs $503648 \mathrm{TL}$, but M-E costs $607951.6 \mathrm{TL}$, thus, M-E requires approximately 20.71\% more cost than the standard design. Considering the excessive budget that has been invested in the maintenance and rehabilitation of highways in Turkey, it could be anticipated that AASHTO'93 underestimates the layer thicknesses in some cases as revealed in this study.

\subsection{Monitoring the Benefits of Switching to the M-E design Method}

To better understand the benefits of switching to the M-E method, it is necessary to compare the optimized M-E designs using the AASTHOWare with those traditional ones determined by the AASHTO'93 method. As discussed above, IRI, TR, and FC values would be the performance indicators to be discussed against the total pavement thickness, which is a strong indicator of the cost of the pavement, and upcoming maintenance and rehabilitation. Since the traditional AASHTO'93 approach utilizes basic parameters and outputs, it does not provide the selected three performance indicators, directly. But it is possible to estimate those values, by simply running the traditional pavement design layer thickness in the AASTHOWare. Ultimately, this would allow us the comparisons of the best designs from the M-E and AASTHO'93 over the same performance indicators.

For the case of three CLs in Turkey the M-E based optimized designs (ME_Izm, ME_Erz, and ME_Riz) were run to get the IRI, TR, and FC values, which are compared with the estimated ones for the AASTHO'93 based designs (93_Erz, 93_Izm and 93_Riz). The performance of both approaches is illustrated in Figure 7 . Since the surface and the subbase course layers were kept the same with $5 \mathrm{~cm}$ and $20 \mathrm{~cm}$, respectively, the x-axis was selected as the total thickness of the binder, bituminous base, and base layers, only in all designs. In the AASHTO'93 method, only 5 different total thickness cases were created based on the input variables (denoted by the blue triangles in Figure 7). The overestimation/underestimation of performance indicators can be easily detected by comparing the desired levels shown by thick lines in the graphs. For example, some of the 93_Izm and 93_Erz designs are expected to have worse IRI than the $2.7 \mathrm{~mm} / \mathrm{km}$ limit. The designs exceeding the limits were mostly the high traffic load (AADT-15000) or medium traffic load (AADT-7500) and high-reliability requirements (95\%). A similar pattern was also detected in the case of the rutting performance of the traditional designs, going above the limit of $19 \mathrm{~mm}$. For the FC, the traditional approach produced the highest value 18 $\mathrm{mm} / \mathrm{km} \mathrm{FC}$ which was still much lower than the allowed $25 \mathrm{~mm} / \mathrm{km}$, suggesting an extremely high overdesign from the fatigue performance perspective. When the optimized M-E designs were analyzed, the performance indicators were satisfied with the majority of the cases that also indicated much more total thickness due to the sensitivity of the model to various variables. For all three CLs, rutting performance was seemed to be the limiting value for most of the design cases, which were more critical for the CL1(Izm) and CL2(Erz). For the case of CL3(Riz), the M-E optimized results were obtained by much smaller pavement thickness without violating the desired performance limits. Besides the TR, FC performance values could be critical but lower than the allowed limit of $25 \mathrm{~mm} / \mathrm{km}$ for most of the cases in the CL3(Riz). For the other two regions, IRI performance was observed as the second critical factor causing mostly higher pavement thicknesses, whereas optimized designs would have much safer FC values than the allowed limit. 


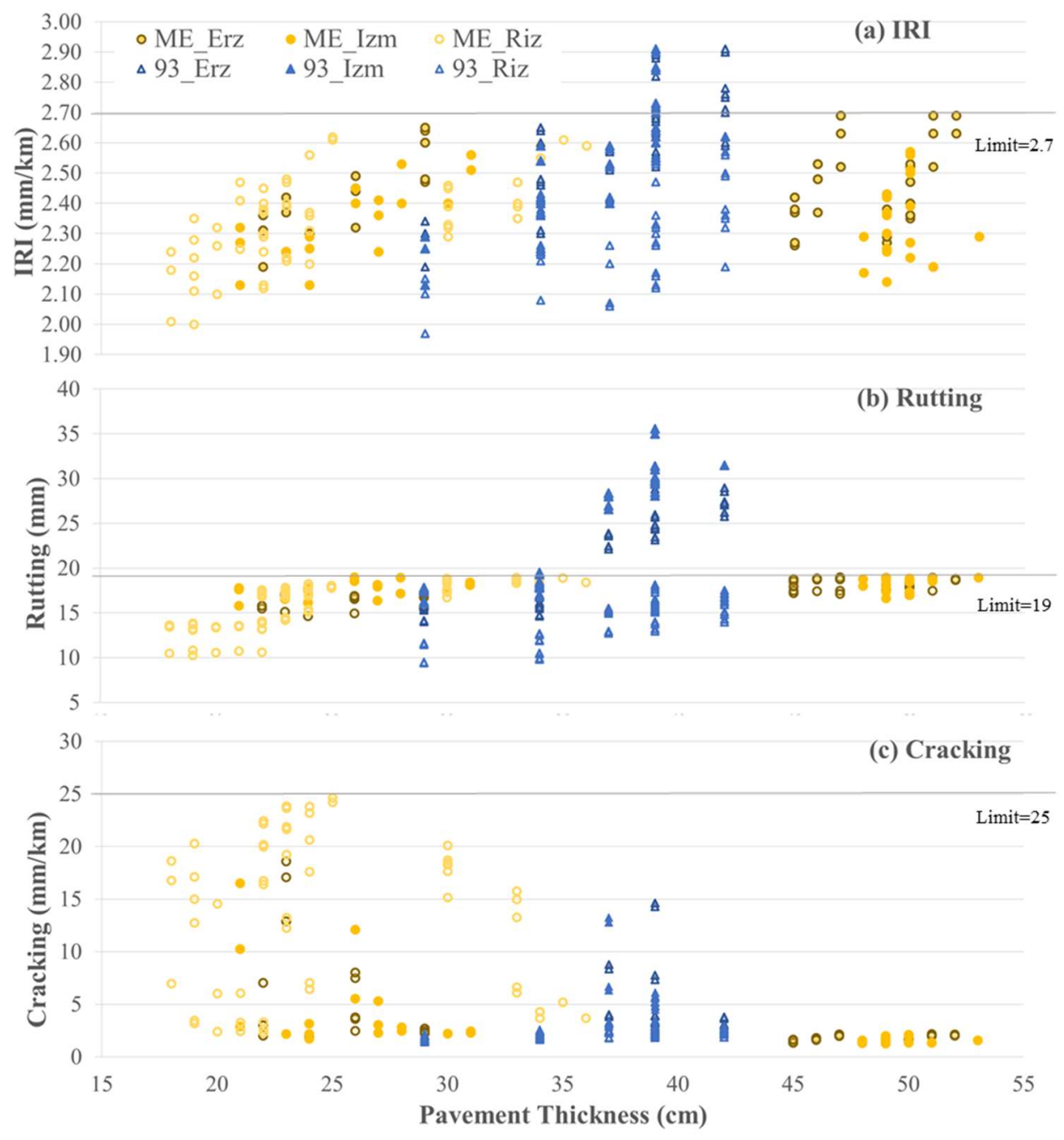

Figure 7 - Total thickness versus performance indicator effects

The pavement thickness change (DT) created using the M-E design is shown in Figure 8, where major reductions can be seen for the CL3(Riz), and drainage should be handled carefully. Higher pavement thicknesses for some of the cases in the M-E design compared to those in the AASTHO'93 method stemmed from the need to satisfy all three performance indicator limits, one or two of which were not met in the latter methodology (see Figure 8). Though the initial cost of these designs with the M-E method would be higher, they are expected to have a higher advantage when the total costs during the service life and quality of the service were considered. 


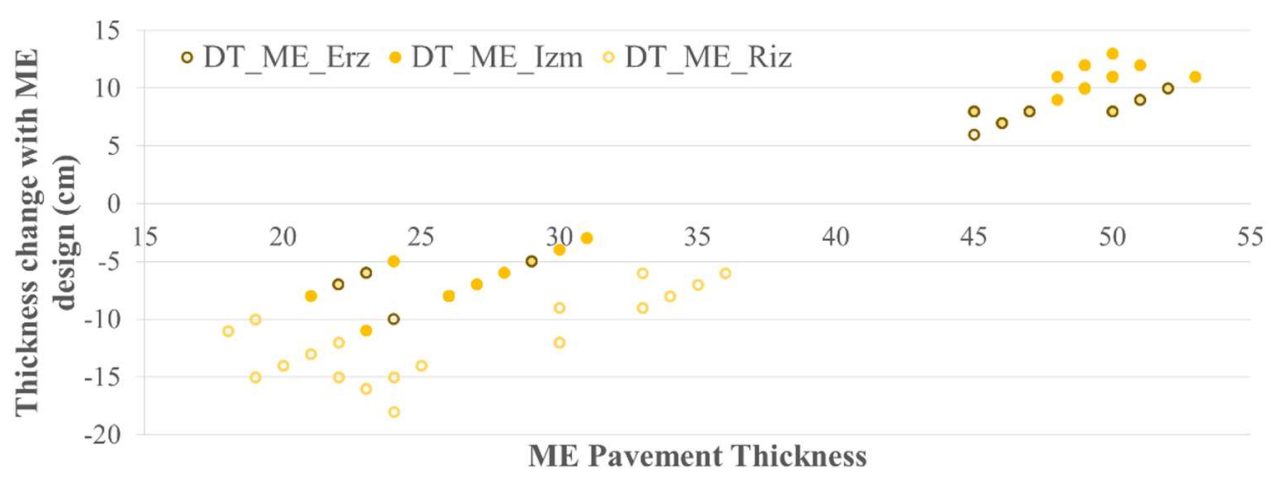

Figure 8 -Total thickness change due to use of the M-E design method

\section{CONCLUSIONS AND FUTURE RECOMMENDATIONS}

Developing countries need expanding their road network, as well as improving their existing road network. Budget limitations result in bigger challenges not only for the construction but also for the maintenance of the roadway networks. Due to its practicality, AASHTO'93 is currently in use in many countries, like Turkey. However, the AASHTO'93 method leads to overestimate or underestimate the layer design thicknesses, which may even result in poor pavement performance and/or high initial construction costs. As this method is empirical, it does not deeply take into account the project-specific properties like the climate, axle load distributions, etc. Thus, the main focus of this study is to implement the M-E analysis method in flexible pavements and state the differences from the current design method for Turkey. Although it has been suggested to calibrate the inputs of AASHTOWare based on regionspecific properties, in this study, the global averages provided by AASHTO'93 were used due to the unavailability of the data. Therefore, comparative analysis based on different climatic regions, traffic patterns, subgrade types, reliability levels, and material choices are done for 20-year service life by utilizing new M-E and traditional AASHTO'93 design methods. Accordingly, the following findings are obtained:

- In all climatic conditions studied, thicker layer designs were predicted in the M-E pavement designs with high traffic volumes and poor soil conditions as compared to designs with AASHTO'93. This is parallel to the findings of the previous studies which reported that climate, subgrade, and traffic volume are the major parameters that influence the design thicknesses. Since realistic climatic properties are used in the M-E analysis, the findings indicated the influence of climate, as well as the poor side of AASHTO’93.

- In flexible pavement design, the mix gradation and the asphalt cement grade selection are critical in performance, as well as the design thickness selection. Because the asphalt grade selection depends majorly on the climatic conditions, the climate effect on the performance grade selection should be considered simultaneously.

- The results indicated that denser gradation with fewer air voids performed better compared to finer gradation with higher void content as expected. Therefore, better 
mixture performance led to a thinner section. However, the influence of material characteristics cannot be taken into account in AASHTO'93 design.

- For low traffic volumes, the M-E design approach may produce more economical designs than those by the AASHTO'93 for Turkey; and, the current practice may be resulting in under-design situations of higher traffic conditions, whereas the M-E design method predicted higher layer thickness than AASHTO'93.

- Thus, it is revealed the importance that shifting from empirical design (AASHTO'93) to new M-E (AASHTOWare) may improve the overall design process and infrastructure budget allocation in developing countries, such as Turkey.

It should be noted that, in this study, some default values (e.g., subgrade properties) are used in the analysis, due to the unavailability of project-specific or regional data, though the analysis indicated the differences when the climatic properties varied from the region to region. As the M-E method is not currently in use in Turkey, climatic data for selected regions was not available, but it was assumed by matching weather station data from three cities in Turkey (Izmir-warm, Erzurum-cold, and Rize-rainy) with three similar weather stations in the US, as adapted by other studies considering the use of the M-E method for regions outside the US. However, since climatic conditions showed the strongest effect on the pavement design and performance, it is a critical step to use local data sets and produce calibration values for the M-E procedure and AASHTOWare to nationally adapt to the new design method. Thus, the challenges for changing the current design practice in Turkey are to develop climatic, material, subgrade, structural data library, as well as to analyze the current road network characteristics including distresses and propagation of distresses through the life of the pavement. Hence, the nationwide calibration of the M-E can be done for Turkey and the M-E can be used as a design method. Due to the presented limitations of the study, it is shown that thicker or thinner pavement layers can be designed when climatic, material, subgrade properties are considered. Thus, it will provide long-life pavements as well as economical savings.

\section{Acknowledgment}

Authors thanks to "Turkish Cement Manufacturers" Association (TCMA)" for their support in the recruitment process of AASHTOWare Pavement M-E Design software (Version 2.2) license.

\section{References}

[1] OECD, Fostering Investment in Infrastructure Lessons learned from OECD Investment Policy Reviews, 2015.

[2] AASHTO, AASHTO Guide for Design of Pavement Structures", American Association of State Highway and Transportation Officials, Washington, D.C. U.S.A., ISBN-10: 1-56051-055-2, 640 pp, 1993. 
[3] NCHRP, Mechanistic-Empirical Design of New and Rehabilitated Pavement Structures, National Cooperative Highway Research Program, NCHRP Project 1-37A Report, National Research Council. Washington, D.C., 2004.

[4] Rahman, M. M., Gassman, S. L., Data collection experience for preliminary calibration of the AASHTO pavement design guide for flexible pavements in South Carolina, International Journal of Pavement Research and Technology, 11(5), 445-457, 2018. https://doi.org/10.1016/j.ijprt.2017.11.009

[5] NCHRP, Recommended Practice for Local Calibration of the M-E Pavement Design Guide, National Cooperative Highway Research Program, ARA Inc. Texas, 2007.

[6] Caliendo, C., Local calibration and implementation of the mechanistic-empirical pavement design guide for flexible pavement design, Journal of Transportation Engineering, 138(3), 348-360, 2011. https://doi.org/10.1061/(ASCE)TE.19435436.0000328

[7] Zofka, A., Urbanik, A., Maliszewski, M., Bankowski, W., Sybilski, D., Site specific traffic inputs for mechanistic-empirical pavement design guide in Poland, (No. 144534), 2014.

[8] Haponiuk, B., Zbiciak, A., Mechanistic-empirical asphalt pavement design considering the effect of seasonal temperature variations, Archives of Civil Engineering, 62(4), 3550, 2016. https://doi.org/10.1515/ace-2015-0096

[9] Plescan, E., Plescan, C., Implementation of mechanistic empirical pavement design guide ME-PDG in Romania, Bull. Transilvania Univ. Braşov, 7(56), 323-329, 2014.

[10] Masad, E., Kassem, E., Little, D., Characterization of asphalt pavement materials in the State of Qatar: A case study, Road Materials and Pavement Design, 12(4), 739-765, 2011. https://doi.org/10.1080/14680629.2011.9713893

[11] Sadek, H. A., Masad, E. A., Sirin, O., Al-Khalid, H., Sadeq, M. A., Little, D., Implementation of mechanistic-empirical pavement analysis in the State of Qatar, International Journal of Pavement Engineering, 15(6), 495-511, 2014. https://doi.org/10.1080/10298436.2013.837164

[12] Aguib, A., Flexible pavement design AASHTO 1993 versus mechanistic-empirical pavement design. MSc thesis, The American University in Cairo School of Sciences and Engineering Construction and Architectural Engineering, 2014. Available at: http://dar.aucegypt.edu/handle/10526/3806

[13] Aguib, A. A., Khedr, S., The mechanistic-empirical pavement design: An Egyptian perspective, In: Functional Pavement Design, CRC Press, 2016, pp. 933-942. https://doi.org/10.1201/9781315643274-102

[14] Khattab, A. M., El-Badawy, S. M., Elmwafi, M., Evaluation of Witczak E* predictive models for the implementation of AASHTOWare-Pavement ME Design in the Kingdom of Saudi Arabia, Construction and Building Materials, 64, 360-369, 2014. https://doi.org/10.1016/j.conbuildmat.2014.04.066 
[15] Shakhan, M. R., Topal, A., Sengoz, B., Data Collection for Implementation of the MechanisticEmpirical Pavement Design Guide (MEPDG) in Izmir, Turkey, Teknik Dergi, 2021. https://dx.doi.org/10.18400/tekderg.651399

[16] Ozturk, H. I., Tan, E. B., Sengün, E., Yaman, I. O., Comparison of jointed unreinforced rigid pavement systems designed with mechanistic-empirical (ME) method for different traffic, soil, material and climatic conditions, Gazi Üniversitesi MühendislikMimarlık Fakültesi Dergisi, 2018. https://doi.org/10.17341/gazimmfd.416536

[17] Kim, D., Nantung, T., Siddiki, N. Z., Kim, J. R., Implementation of new mechanisticempirical design for subgrade materials: Indiana's experience, No. 07-0463, 2007.

[18] Hasan, M. A., Tarefder, R. A., Development of temperature zone map for mechanisticempirical (M-E) pavement design, International Journal of Pavement Research and Technology, 11(1), 99-111, 2018. https://doi.org/10.1016/j.ijprt.2017.09.012

[19] FHWA, Geotechnical Aspects of Pavements Reference Manual, Federal Highway Administration, 2019. https://www.fhwa.dot.gov/engineering/geotech/pubs/05037/ac.cfm Accessed on 4 November 2019

[20] Azadi, M., Nasimifar, S. M., Pouranian, M. R., Determination of local fatigue model calibration used in MEPDG for Iran's dry-no freeze region, Arabian Journal for Science and Engineering, 38(5), 1031-1039, 2013. https://doi.org/10.1007/s13369-012-0340-0

[21] Li, Q. J., Wang, K. C., Yang, G., Zhan, J. Y., Qiu, Y., Data needs and implementation of the Pavement ME Design, Transportmetrica A: Transport Science, 1-30, 2018. https://doi.org/10.1080/23249935.2018.1504254

[22] Rao, K. V., Mathew, T., Flexible Pavement Design, Introduction to Transportation Engineering Lecture Notes, 2007.

[23] AASHTO, Mechanistic-empirical pavement design guide: A manual of practice, American Association of State Highway and Transportation Officials, 2008a.

[24] Carvalho, R., Schwartz, C., Comparisons of flexible pavement designs: AASHTO empirical versus NCHRP Project 1-37A mechanistic-empirical, Journal of the Transportation Research Board, (1947), 167-174, 2006. https://doi.org/10.1177/0361198106194700116

[25] Li, Q., Mills, L., McNeil, S., Attoh-Okine, N., Exploring the impact of climate change on pavement performance and design, Presented at the Transportation Research Board 91st Annual Meeting, 2012.

[26] Elshaeb, M. A., El-Badawy, S. M., Shawaly, E. S. A., Development and impact of the Egyptian climatic conditions on flexible pavement performance, American Journal of Civil Engineering and Architecture, 2(3), 115-121, 2014. https://doi.org/10.12691/ajcea-2-3-4

[27] AASHTO, Mechanistic-Empirical Pavement Design Guide, AASHTO Designation: MEPDG-1, American Association of State Highway and Transportation Officials, Washington, D.C, 2008b. 
[28] Elshaeb, M. A., El-Badawy, S. M., Shawaly, E. S. A., Development and impact of the Egyptian climatic conditions on flexible pavement performance, American Journal of Civil Engineering and Architecture, 2(3), 115-121, 2014. https://doi.org/10.12691/ajcea-2-3-4

[29] Shafiee, M. H., Hashemian, L., Rostami, A., Bayat, A., Tabatabaee, N., Field measurement and modeling of vertical and longitudinal strains from falling weight deflectometer testing, Journal of Transportation Engineering, Part B: Pavements, 144(1), 2017. https://doi.org/10.1061/JPEODX.0000022

[30] Jannat, G. E., Database Development for Ontario's Local Calibration of MechanisticEmpirical Pavement Design Guide (MEPDG) Distress Models, MSc thesis, Ryerson University, 2012. Available at: https://digital.library.ryerson.ca/islandora/object/RULA\%3A1461

[31] Hossain, N., Singh, D., Zaman, M., Rassel, S. S., Local calibration of MEPDG rut models: Oklahoma's experience from an instrumented pavement section. Analytical Methods in Petroleum Upstream Applications, 135, 2015. https://doi.org/10.1201/b17435-20

[32] Pereira, P., Pais, J., Main flexible pavement and mix design methods in Europe and challenges for the development of a European method, Journal of Traffic and Transportation Engineering (English Edition), 4(4), 316-346, 2017. https://doi.org/10.1016/j.jtte.2017.06.001

[33] Montuschi, A., Dondi, G., Pettinari, A. R. M., Flexible pavement design using Mechanistic-Empirical methods: the Californian approach, MSc thesis, Department of Civil, Chemical, Environmental and Material Engineering, Alma Mater Studiorum University of Bologna, 2012. Available at: https://amslaurea.unibo.it/4914/1/tesi_file_unico.pdf

[34] Aflaki, S. Tabatabaee, N., Proposals for modification of Iranian bitumen to meet the climatic requirements of Iran, Construction and Building Materials, 23(6), 2141-2150, 2009. https://doi.org/10.1016/j.conbuildmat.2008.12.014

[35] Saglik, A., Orhan, F., Gungor, A. G., BSK Kaplamalı Yollar İçin Bitüm Sınıfı Seçim Haritaları (Bitumen Class Selection Maps for BSK Coated Roads), General Directorate of Highways, 2012. Available at: http://www.kgm.gov.tr/

[36] Dezotepe, G., Ksaibati, K., The Effect of Environmental factors on the implementation of the Mechanistic-Empirical Pavement Design Guide, Wyoming Technology Transfer Center, 2011.

[37] Turkish State Meteorological Service (TSMS), Weather Statistic for 1950-2015 Period in City: Normal and Extreme Recordings, 2017. Retrieved on Augustus 15, 2017, Available at: the https://www.mgm.gov.tr/

[38] GDH, Trafik ve Ulaşım Bilgileri (Traffic and Transportation Information), General Directorate of Highways, 2019. Available at: http://www.kgm.gov.tr/

[39] GDH, Karayolları Esnek Üstyapılar Projelendirme Rehberi (Flexible Pavement Design Guide for Highways), General Directorate of Highways, Ankara, 93, 7, 2008. 
[40] Kottek M., Grieser J., Beck C., Rudolf B., Rubel F., World Map of the Köppen-Geiger Climate Classification Updated, Meteorol Zeitschrift, 15:259-63, 2006.

[41] Mehta, Y. A., Sauber, R. W., Owad, J., Krause, J., Lessons learned during implementation of mechanistic-empirical pavement design guide, No. 08-1670, 2008.

[42] Mubaraki, M., Study the relationship between pavement surface distress and roughness data, In MATEC Web of Conferences (Vol. 81, p. 02012), EDP Sciences, 2016.

[43] Lin, J. D., Yau, J. T., Hsiao, L. H., Correlation analysis between international roughness index (IRI) and pavement distress by neural network, In 82nd Annual Meeting of the Transportation Research Board (pp. 12-16), 2003.

[44] KGM 2020 Birim Fiyatları (Item Numbers of GDH for 2020), 2021, Retrieved on April 01, 2021. Available at: https://www.birimfiyat.net/ 
